\title{
The effect of warm compress intervention on post herniotomy pain
}

\author{
Ika Cahyaningsih ${ }^{1}$, Wenny Savitri ${ }^{2}$, R. Anggono Joko Prasojo ${ }^{3}$ \\ ${ }^{1,3}$ Medical and Surgical Nursing Department of Wates Kulon Progo District General Hospital of Yogyakarta, Indonesia \\ ${ }^{2}$ Department of Nursing, Universitas Jenderal Achmad Yani Yogyakarta, Indonesia
}

\begin{tabular}{l} 
ARTICLE INFO \\
\hline Article history: \\
Received: August 9, 2020 \\
Revised: August 20, 2020 \\
Accepted: August 30, 2020 \\
\hline
\end{tabular}

Keywords:

Warm compress intervention; Complementary therapy; Herniotomy; Pain intervention.

\begin{abstract}
The most complaint symptom for post herniotomy patients is pain on the surgical site. Pain may affect patients' ability to mobilize and may attribute to prolonged length of stay in the hospital. Many complementary therapies have been used to decrease pain intensity for patients post-surgery, but warm compress intervention on post herniotomy pain has not been explored significantly. To investigate the effect of warm compress intervention on post herniotomy pain. The study used a pre-post test quasi-experimental with control group design. Sixteen post herniotomy adult patients of Wates Kulon Progo District General Hospital of Yogyakarta were recruited for each group. The intervention group was given warm compress interventions two times per day for two days. Pain intensity was assessed pre and post-intervention with the Numerical Rating Scale, while the control group only received regular analgetic. The researchers used the Wilcoxon Signed-Rank Test and Mann-Whitney U Test to compare pain intensity in each group and between groups.Fifteen out of 16 patients who received warm compress intervention rated decreased pain intensity as the rest did not experience any differences after the intervention $(\mathrm{Z}=-3.354, p=.001)$. Unlike the control group, only 3 out of 16 patients experienced declined pain intensity after two days of herniotomy when the rest did not encounter any changes $(\mathrm{Z}=-1.732, p=.083)$. The mean rank between intervention and control groups were significantly different $(\mathrm{U}=20.000, p=.000)$. Warm compress intervention is a non-invasive nursing intervention which is effective in reducing the pain intensity of post herniotomy patients.
\end{abstract}

This work is licensed under a Creative Commons Attribution 4.0 International License.

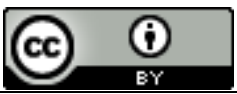

\section{Corresponding Author:}

Wenny Savitri,

Department of Nursing,

Universitas Jenderal Achmad Yani Yogyakarta,

Jl. Siliwangi, Ringroad Barat, Banyuraden, Gamping, Sleman

Daerah Istimewa Yogyakarta Indonesia 55293

Email: wenny.savitri1@gmail.com

\section{INTRODUCTION}

The main Pain following surgical procedures has aroused growing concern in the past few decades. Thirty to forty percent of patients suffer from severe post-operative pain, even though this experience varies among genetics, social, and cultural backgrounds. Acute pain as in post-operative pain following herniotomy is a symptom derived from tissue insult caused by the surgical procedure. It triggers neuroendocrine, immune, and inflammatory responses, which leads to a deterioration of vegetative signs, psychological response, and changes in behavior [1]. This, it is necessary to manage post-operative pain in order to facilitate early mobilization and discharge patients from hospital to outpatient care and reduce post-operative complications. Beside treating post-operative pain with analgesia, non-pharmacological methods have been used widely to decrease the pain including psychological methods hypnosis [2], distraction [3], and biofeedback [4], or physical methods cold [5], heat [6], massage [7], acupuncture [8], and transcutaneous electrical nerve stimulation (TENS) [9]. 
Herniotomy is one of the most frequent surgeries done in Wates Kulonprogo District General Hospital of Yogyakarta. Most patients complained about post-operative pain to nurses. A cohort study through patients' record in post-operative patients undergoing open repair of complex ventral hernias suggested that the patients still have complaints of pain during the first year after the surgery [10]. The type of pain in post herniotomy patients is moderate pain of shorter duration. One important issue which needs to be addressed is to prevent the development of chronic post herniorrhaphy inguinal pain (CPIP). It is one of the most clinical outcomes which can increase patient satisfaction and quality of life. Medical approaches such as ilioinguinal nerve excision [11] and maintaining three inguinal nerves namely ilioinguinal, iliohypogastric, and genital branch of genitofemoral nerve have been recommended to prevent chronic pain after inguinal hernia repair [12]. Warm compress as a complementary therapy is rarely applied to decrease post-operative pain while this therapy is natural, costs little, and can be applied independently by nurses to patients to relieve pain intensity. This study intended to investigate the effect of warm compress intervention on post herniotomy pain.

\section{RESEARCH METHOD}

\subsection{Study Design}

The current study is quasi-experimental, using pre-test and post-test with control group design.

\subsection{Setting}

The study took place in Wates Kulonprogo District General Hospital of Yogyakarta for a month.

\subsection{Participant Selection: Size, Recruitment Procedures, and Characteristic}

Researchers randomly assigned 16 participants for each group who were adult, post herniotomy day 1, stable, able to read, write, and communicate verbally, not using other non-pharmacological techniques to reduce pain, and undergone spinal anesthesia. The exclusion criteria were laparoscopic herniotomy.

\subsection{Protocol and Data Collection}

The experimental group participants were then given warm compress of $40^{\circ} \mathrm{C}-43^{\circ} \mathrm{C}$ water, filled inside a pouch, placed $10 \mathrm{~cm}$ upper incision area in the right or left side of inguinal for 10 minutes. The intervention was delivered two times a day for two days; every seventh-hour post standardized hospital analgesia was given. Pain intensity was always assessed using the Eleven-point numerical rating scale (NRS 0-10) pre and post warm compress interventions [13]. Meanwhile, the control group was only given standardized pain management using intravenous Ketorolac every 8 hours for the first day and then followed by an oral tablet of Mefenamic Acid 3x500mg since day 2 post-surgery. The pain intensity was also measured at the same protocol as the intervention group.

\subsection{Data Analysis}

The frequency was used to describe the distribution of univariate data, while the Wilcoxon SignedRank Test and Mann-Whitney U Test were used to compare pain intensity in each group and between groups with $95 \%$ confidence interval.

\section{RESULTS AND DISCUSSIONS}

The mean age of the participants' in the control group was 51.25 years old, whereas, in the intervention group was 62.56 years old, but the range of the age was not quite different. Most of the participants were male and diagnosed with an inguinal hernia, as shown in table 1.

Table 1. Characteristics of Participants

\begin{tabular}{lcc}
\hline \multirow{2}{*}{ Characteristic } & Control Group & Intervention Group \\
\cline { 2 - 3 } & Result & Result \\
\hline Age & $51.25 \pm 18.55$ & $62.56 \pm 15.95$ \\
Sex & Min-max 21-80 & Min-max 21-82 \\
Male & & \\
Female & $14(87.5 \%)$ & $14(87.5 \%)$ \\
Diagnosis & $2(12.5 \%)$ & $2(12.5 \%)$ \\
Inguinal hernia & $14(87.5 \%)$ & \\
Femoral hernia & $2(12.5 \%)$ & $15(93.75 \%)$ \\
\hline
\end{tabular}


The Wilcoxon test data, as seen in table 2, depicted that $93.75 \%$ of participants in the intervention group had a negative rank of pain intensity, which means that after four consecutive warm compress interventions, the patients' pain intensity had declined. The statistical test also showed a significant difference in the mean rank of pain intensity in the intervention group $(Z=-3.354, p=.001)$. In contrast with the control group, only $18.75 \%$ of participants were revealed to have a negative rank while the rest had ties. The statistical test showed no difference in the mean rank of pain intensity in the control group $(\mathrm{Z}=-1.732, p=.083)$.

Table 2. Pain Intensity Difference within Group

\begin{tabular}{|c|c|c|c|c|c|c|c|c|c|}
\hline \multirow{2}{*}{\multicolumn{2}{|c|}{ Pain Intensity Rank }} & \multicolumn{4}{|c|}{ Control Group } & \multicolumn{4}{|c|}{ Intervention Group } \\
\hline & & $\mathbf{f}$ & $\%$ & $\mathbf{Z}$ & p-value & $\mathbf{f}$ & $\%$ & $\mathbf{Z}$ & p-value \\
\hline \multirow[t]{4}{*}{ Post-Pre } & Negative rank & $3^{\mathrm{a}}$ & 18.75 & -1.732 & .083 & $15^{\mathrm{a}}$ & 93.75 & -3.354 & 0.001 \\
\hline & Positive rank & $0^{\mathrm{b}}$ & 0 & & & $0^{\mathrm{b}}$ & 0 & & \\
\hline & Ties & $13^{\mathrm{c}}$ & 81.25 & & & $1^{\mathrm{c}}$ & 6.25 & & \\
\hline & Total & 16 & 100 & & & 16 & 100 & & \\
\hline
\end{tabular}

a. Post < Pre; b. Post > Pre; c. Post $=$ Pre

The results from the Mann-Whitney U Test, as seen in table 3, showed a significant statistical mean difference in pain intensity between participants in the intervention group and the control group $(U=20.000, p=.000)$. Based on Cohen's d, the calculated effect size of intervention was 2.98 which falls into large criterion. The lower and upper confidence interval were 1.97 and 3.98 respectively. It shows that the intervention is effective to lessen pain intensity of the participants and has promising effect to be applied to other setting.

Table 3. Pain Intensity Difference between Groups

\begin{tabular}{lcccc}
\hline Group & n & Mean Rank & U & p-value \\
\hline Control & 16 & 23.25 & 20.000 & 0.000 \\
Intervention & 16 & 9.75 & & \\
\hline
\end{tabular}

Most participants in the study in the control and intervention groups were adult men with inguinal hernia. It is in accord with previous studies in Medan, Indonesia, where among 345 patients with an inguinal hernia from the year $2005-2015,67.8 \%$ of them were male, and the rest were female [14]. Similar to a study in England, most of the inguinal hernia affects men, while femoral hernia mostly affects women [15].

All of the participants complained post surgery pain with the mean score of $6.19 \pm 1.33$ in control group and 6.88 \pm 1.20 in intervention group which falls into severe pain (NRS 5 -10) [16]. This is in accord to Rawal, mentioning that 2 to $10 \%$ of adults undergoing surgery experience severe pain. The pain can stay leading to persistent post operative pain causing patients disability and finally lower their quality of life [17]. Hernia repair surgery, including herniotomy, is one of the most common surgical operations beside breast and thoracic surgery, leg amputation, and coronary artery bypass surgery that go on to experience chronic pain $(10-50 \%)$. This incidence happened mostly related to injury of nerves in the surgical area during the procedure [18]. The mean score on day- 2 on the last measurement in the control group was $3.44 \pm 0.89$ as compared to $1.63 \pm 0.96$ in the intervention group after 4 consecutive interventions of warm compress. The results suggested without additional intervention beside regular pain management in the hospital, the patients may benefit from the analgesia to reduce their pain intensity from severe to moderate level (NRS 3-4) on day 2. On the other hand, the intervention group which received regular pain management from hospital and the warm compress intervention experienced huge decline of pain intensity from severe to mild level $(0-2)$.

The present study's findings revealed a significant difference in pain intensity of participants in the intervention group before and after the warm compress intervention, even though one participant did not experience any difference in pain intensity after being treated with the warm compress. The participant was male aged 21 year old with lateral inguinal hernia. Previous study in the United States divulged that complementary alternative medicine (CAM) is more preferred to use by women as compared to men $(62.2 \%$ vs. $37.8 \%$ ) [19]. Similar to a study taken place in Ghana suggested that female, young, married, and highly educated patients are more likely to use CAM [20].

Further, the Mann-Whitney $U$ test results also confirmed that there is a significant difference between pain intensity in the control group and intervention group, which means warm compress intervention is effective in reducing pain intensity of post herniotomy patients. The results are in accord with the previous study that applied warm water compress bistage intervention in obstetric patients undergoing vaginal delivery [21]. The study was taken place in Iran to 150 women assigned to the control and experimental group equally. $22.7 \%$ of participants in the intervention group were performed a mediolateral episiotomy. The results showed 
that the mean intensity of pain on the first day after delivery was significantly lower in the intervention group compared with the control group $(p<.001)$.

Essa \& Ismail [22] also concluded that a warm pack could reduce pain intensity. The study was performed to 160 primiparae women assigned into control and experimental group in a 1:1 ratio. The experimental group received usual care during the first stage of labor, and then on the second stage, the warm perineal compress was applied. The results showed that perineal pain intensity had decreased following warm compress in the experimental group $(p=.106)$.

R.R.Krowa conducted a study performing warm compress intervention to 30 women following cesarean section divided equally into control and experimental groups. The experimental group women were given warm water compress $40-43^{\circ} \mathrm{C}$ around the incision for 5-10 minutes in 3 days using warm water pouch. The results indicated a progressive decline of pain intensity day by day in the experimental group. The T-test results between the control group and the experimental group also indicated a significant difference in pain intensity between groups. In conclusion, the warm compress intervention was sufficient to decrease pain intensity for post-cesarean section patients.

Similarities among the present study results and those mentioned above could be attributed to what is obtained in the literature about the encouraging therapeutic effects that heat produces. Heat therapy, including warm compress, is believed able to relax muscle spasm [1], dilates blood vessels, and escalates blood flow. It can influence the transmission of pain impulses by reducing local ischemia caused by muscle spasm or tension. Warm compress can also stimulate the release of Endorphin $\beta$ levels which blocks the sensation of pain [23]. However, the success of implementation of complementary therapy, including the warm compress, is not easy. Health providers need to use structured approach by constructing shared decision making in utilizing complementary therapy as part of patients' post operative pain management since the patients' values remain ideal in this process. The evidence of safety and efficacy, cost, conflict and care context are also important information to deliver prior applying the therapy [24].

\section{CONCLUSION}

The warm compress intervention is effective with the effect size of 2.98 in reducing pain intensity of post herniotomy patients. Further studies, including changes in vegetative signs, the psychological response, and changes in behavior, need to be investigated.

\section{Acknowledgements}

We are thankful to the rector of Universitas Jenderal Achmad Yani Yogyakarta, Director of Wates Kulon Progo District General Hospital of Yogyakarta, and all of respondents who had facilitated the research.

\section{REFERENCES}

[1] J. Malek, P. Sevcik, D. Bejsovec and J. Gabrhelik, "Postoperative Pain Management," 2017. [Online]. Available:

https://www.wfsahq.org/components/com_virtual_library/media/125136f77e1b7daf7565bd6653026c 35-Postoperat. [Accessed 15 August 2020].

[2] C. Kendrick, J. Sliwinski and A. Johnson, "Hypnosis for Acute Procedural Pain: A Critical Review," International Journal of Clinical and Experimental Hypnosis, vol. 64, pp. 75-115, 2016.

[3] A. Gupta, A. Scott and M. Dukewich, "Innovative Technology Using Virtual Reality in the Treatment of Pain: Does It Reduce Pain via Distraction, or Is There More to It?," Pain Medicine, vol. 19, pp. 151$159,2018$.

[4] T. J. Wang, C. F. Chang and M. F. Lou, "Biofeedback Relaxation for Pain Associated With Continuous Passive Motion in Taiwanese Patients After Total Knee Arthroplasty," Research in Nursing and Health, vol. 38, pp. 39-50, 2015.

[5] Y. Zeng, Y. Li and J. H. Gao, "Application of a cold patch for relieving pain after transepithelial photorefractive keratectomy," Pain Res Manag, vol. 20, pp. 195-198, 2015.

[6] Y. R. Krowa and W. Savitri, "Kompres hangat untuk pasca operasi Sectio Caesarean," Media Ilmu Kesehatan, vol. 2, pp. 21-24, 2013.

[7] R. M. Essa and N. A. Ismail, "Effect of second stage perineal warm compresses on perineal pain and outcome among primiparae," Journal of Nursing Education and Practice, vol. 6, pp. 48-58, 2015.

[8] Y. H. Cho, K. Kim, K. H. Heo and M. S. Lee, "Acupuncture for acute postoperative pain after back surgery: A systematic review and meta-analysis of randomized controlled trials," Pain Practice, vol. 15, pp. 279-291, 2015. 
[9] A. Fiorellia, F. Morgillob, R. Milionea and M. C. Pac, "Control of post-thoracotomy pain by transcutaneous electrical nerve stimulation: effect on serum cytokine levels, visual analogue scale, pulmonary function and medication," European Journal of Cardio-Thoracic Surgery, vol. 41, pp. 861868, 2012.

[10] C. G. DeLong, J. A. Doble and A. L. Schilling, "Delineating the burden of chronic post-operative pain in patients undergoing open repair of complex ventral hernias," The American Journal of Surgery, vol. 215, pp. 610-617, 2018.

[11] A. Johner, J. Faulds and S. M. Wiseman, "Planned ilioinguinal nerve excision for prevention of chronic pain after inguinal hernia repair: A meta-analysis," Surgery, vol. 150, pp. 534-541, 2011.

[12] A. Alfieri, P. K. Amid, G. Campanelli and G. Izard, "International guidelines for prevention and management of post-operative chronic pain following inguinal hernia surgery," Hernia, vol. 15, pp. 239 - 249, 2011.

[13] R. Chou, D. B. Gordon and L. Casasola, "Management of Postoperative Pain: A Clinical Practice Guideline From the American Pain Society, the American Society of Regional Anesthesia and Pain Medicine, and the American Society of Anesthesiologists' Committee on Regional Anesthesia," The Journal of Pain, vol. 17, pp. 131-157, 2016.

[14] G. Sinalthan, "Karakteristik Hernia Inguinalis Pada Anak di Rumah Sakit Umum Pusat Haji Adam Malik Medan Periode 2005-2015," Universitas Sumatera Utara, Medan, 2017.

[15] R. J. Fitzgibbons and R. A. Forse, "Groin Hernias in Adults," New England Journal of Medicine, vol. 372, pp. 756-763, 2015.

[16] H. J. Gerbershagen, J. Rothaug and C. J. Kalkman, "Determination of moderate-to-severe postoperative pain on the numeric rating scale: a cut-off point analysis applying four different methods," British Journal of Anaesthesia, vol. 107, pp. 619 - 26, 2011.

[17] N. Rawal, "Current issues in postoperative pain management," European Journal of Anaesthesiology, vol. 33, pp. 160 - 171, 2016.

[18] Institute of Medicine, Relieving Pain in America, Washington, D.C: The National Academies Press, 2011.

[19] M. Alwhaibi, Y. AlRuthia and A. M. Meraya, "Gender Differences in the Prevalence of Complementary and Alternative Medicine Utilization among Adults with Arthritis in the United States," Evidence-Based Complementary and Alternative Medicine, vol. 2019, pp. 1-11, 2019.

[20] J. Yarney, A. Donkor, S. Y. Opoku and L. Yarney, "Characteristics of users and implications for the use of complementary and alternative medicine in Ghanaian cancer patients undergoing radiotherapy and chemotherapy: a cross- sectional study," BMC Complementary and Alternative Medicine, vol. 13, 2013.

[21] M. Akbarzadeh, F. Vaziri, M. Farahmand and Z. Masoudi, "The Effect of Warm Compress Bistage Intervention on the Rate of Episiotomy, Perineal Trauma, and Postpartum Pain Intensity in Primiparous Women with Delayed Valsalva Maneuver Refferring to the Selected Hospitals of Shiraz University of Medical Sciences," Advances in Skin \& Wound Care, vol. 29, pp. 79-84, 2016.

[22] R. M. Essa and N. A. Ismail, "Effect of second stage perineal warm compresses on perineal pain and outcome among primiparae," Journal of Nursing Education and Practice, vol. 6, pp. 48-58, 2015.

[23] Mukhoirotin, Kurniawati and F. D. Ayu, "The effects of cold compress and warm compress on $\beta$ endorphin levels, IL-6 and TNF $\alpha$ among adolescent with dysmenorrhea," Indian Journal of Public Health Research and Development, vol. 9, pp. 474-479, 2018.

[24] L. L. Jansons, L. R. Lynch and A. LeBlanc, "Shared Decision Making in Complementary and Alternative Medicine Therapies," Pediatric Annals, vol. 41, pp. 522-527, 2012. 